\title{
Scaffold Stiffness Influences Cell Behavior: Opportunities for Skeletal Tissue Engineering
}

\author{
Roel G.M. Breuls ${ }^{1,3}$, Timothy U. Jiya ${ }^{2,3}$, and Theo H. Smit ${ }^{*}, 1,3$ \\ ${ }^{I}$ Department of Physics and Medical Technology, VU University Medical Center, Research Institute MOVE, \\ Amsterdam, The Netherlands \\ ${ }^{2}$ Department of Orthopedics, VU University Medical Center, Amsterdam, The Netherlands \\ ${ }^{3}$ Sketetal Tissue Engineering Group Amsterdam (STEGA), The Netherlands
}

\begin{abstract}
Skeletal defects resulting from trauma, tumors, or abnormal development frequently require surgical treatment to restore normal tissue function. To overcome the limitations associated with conventional surgical treatments, several tissue engineering approaches have been developed. In particular, the use of scaffolds enriched with stem cells appears to be a very promising strategy. A crucial issue in this approach is how to control stem cell behavior. In this respect, the effects of growth factors, scaffold surface characteristics, and external 'active' loading conditions on stem cell behavior have been investigated. Recently, it has become clear that the stiffness of a scaffold is a highly potent regulator of stem cell differentiation. In addition, the stiffness of a scaffold affects cell migration, which is important for the infiltration of host tissue cells. This review summarizes current knowledge on the role of the scaffold stiffness in the regulation of cell behavior. Furthermore, we discuss how this knowledge can be incorporated in scaffold design which may provide new opportunities in the context of orthopedic tissue engineering.
\end{abstract}

Keywords: Orthopaedics, tissue engineering, scaffold, substrate stiffness, cell mechanics, bone, cartilage, tendon, mechanotransduction.

\section{INTRODUCTION}

Skeletal defects as a result of injury or disease form a significant problem in health care with major socioeconomic impacts. Considering bone defects, traditional treatment modalities often use autograft and allograft cancellous bone. While these surgical treatments have increased the quality of life for many patients they have some important limitations. The use of autografts may be limited by scarceness of donor tissue and may cause donor site morbidity associated with infection, pain, and hematoma [1-6]. In addition, harvesting autografts requires a second surgical procedure, potentially increasing the risk of complications and cost of treatment. Allograft bone introduces the risk of host rejection and infection [7-11] and may also suffer from a limited supply. Restoration of cartilage and ligaments with autografts and allografts largely suffer from the same limitations.

Tissue engineering has been heralded as an alternative treatment strategy that may circumvent the problems associated with autograft and allograft procedures. Early tissue engineering approaches have used a variety of a-cellular scaffolds, including synthetic scaffold materials fabricated from hydroxyapatite, tricalcium phosphate ceramics, metal alloys, and various polymers such as polylactic acid (PLA) and polyglycolic acid (PGA) [12-15]. Furthermore, natural scaffolds consisting of extracted extracellular matrix (ECM)

*Address correspondence to this author at the Department of Physics and Medical Technology, VU University Medical Center, Research Institute MOVE, Amsterdam, The Netherlands; Tel: 020-4448023;

E-mail: th.smit@vumc.nl proteins such as collagen and fibrin have been used for tissue engineering (reviewed in [16]). The function of these acellular scaffold materials is to provide mechanical stability at the defect site, to stimulate the ingrowth of cells from healthy residual tissues in situ, and to guide the complex process of tissue formation.

A new generation of tissue engineering approaches incorporates the use of cells, which are seeded onto a scaffold to enhance the efficacy of tissue regeneration $[17,18]$. The basic idea in this approach is to harvest cells from a patient, to seed these cells onto a scaffold material, and to subsequently implant the cell-seeded scaffold into the patient. The cells should produce the new tissue while the scaffold material gradually disintegrates, leaving no harmful traces in the body.

Stem cells appear to be one of the most promising cell types to use in engineering applications. A central issue in the utilization of stem cells is how to pursue the stem cells to differentiate into the desired lineage and to restore tissue function. Unfortunately, there is not a simple answer to this question since stem cell differentiation is a highly complex and multi-factorial process. In vivo, stem cells are subjected to a complex array of biophysical and biochemical signals. These signals are processed and 'integrated' by the stem cells to regulate stem cell differentiation (Fig. 1).

It has long been appreciated that soluble biochemicals such as growth factors, cytokines, and chemokines affect the morphogenesis of skeletal tissues. For example, growth factors from the $\mathrm{TGFb}$ superfamily notably the bone morphoge- 


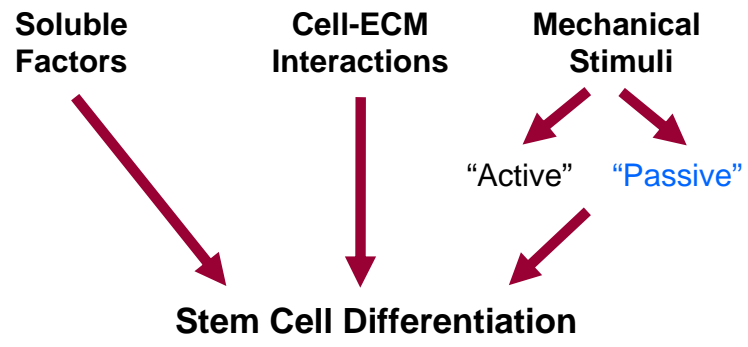

Fig. (1). Stimuli affecting stem cell differentiation. Stem cell differentiation is affected by soluble factors, biochemical cell-matrix interactions, and mechanical stimuli. Mechanical stimuli can be subdivided in 'active' and 'passive'. The 'active' forces are external mechanical forces acting on a scaffold during normal activity. The stiffness of a scaffold is a key 'passive' mechanical cue that affects stem cell differentiation.

netic proteins (BMPs) are highly potent stimulators for skeletal tissue formation (reviewed in [19-24]). Furthermore, ECM proteins such as collagens, glycosaminoglycans, and proteoglycans provide instructive messages to cells that are transmitted across the cell membrane via the transmembrane receptors that recognize these ECM proteins. These cellECM interactions influence cell behavior either directly or through crosstalk with growth factors [25-29]. Furthermore, stem cells have been shown to respond to external mechanical loading (reviewed in [30-32]). For skeletal tissues, these 'active' external mechanical forces are required to maintain normal cell function [33-35]. Physical properties of a scaffold can also influence cell behavior. Examples include surface characteristics such as roughness [36-38], micro- and nano-topography [39, 40], surface energy [37], and porosity [41-44].

Only recently, it has been appreciated that also the stiffness of the ECM is a highly potent regulator of stem cell behavior [45-47]. The stiffness of the ECM acts as a 'passive' mechanical cue that tends to be more selective than soluble factors [47]. This review briefly describes how cells sense the stiffness of a scaffold and discusses the role of the scaffold stiffness in regulating cell behavior. In addition, the influence of scaffold stiffness on cell behavior in combination with biochemical stimuli is considered. Finally, scaffold stiffness is discussed as an opportunity to control cell behavior in the context of skeletal tissue engineering.

\section{SUBSTRATE STIFFNESS}

Cells receive mechanical feedback from the substrate to which they adhere, even in the absence of externally applied forces. Here, 'substrate' refers to any material to which cells adhere, for example the ECM, a scaffold, or a culture flask. In recent years, researchers have been extensively investigating the role of the stiffness of a substrate as one of the key parameters that affects cell behavior. A key motivation for these studies was that cells in vivo often encounter a relatively soft environment, whereas conventional tissue culture flasks are very rigid. This led to the development of $2 \mathrm{D}$ in vitro model systems which use polymer gel substrates with tunable elastic properties that are coated with specific ECM proteins for cell attachment. In particular, polyacrylamide gels have been widely used because these gels can be tuned within a wide range of stiffness that mimic those of in vivo tissues (reviewed in [46, 48-51]). An essential characteristic of these in vitro ECM mimics is that the effects of substrate stiffness and substrate biochemistry on cell behavior can be independently studied. Commonly chosen stiffness values for the PA gels are in the range of $\sim 0.5 \mathrm{kPa}$ (brain tissue), $\sim 10 \mathrm{kPa}$ (muscle tissue), and $>30 \mathrm{kPa}$ (pre-mineralized bone) [46]. These gels are often referred to as 'soft', 'intermediate stiff', and 'stiff'.

\section{Cell Probing of Substrate Stiffness}

Mechanotransduction is the process by which cells convert mechanical stimuli into a chemical response [52]. This plays an essential role in the probing of matrix stiffness and is currently subject of extensive research. It is beyond the scope of this review to provide a detailed description of the highly complex signaling cascades involved in mechanotransduction. Instead, we focus on a basic understanding of how cells probe the stiffness of a substrate. For a more detailed explanation we refer the reader to recent reviews on this topic [45, 53-57]. Cells bind to a substrate with transmembrane molecules called integrins, which have an extracellular domain that attaches to the substrate and an intracellular domain that connects to the cytoskeleton (Fig. 2). When cells bind to the ECM, integrins begin to cluster, which leads to the recruitment of structural and signaling proteins to form so-called focal adhesions at the site of integrin clustering. The formation and maturation of focal adhesions requires the application of mechanical forces to these adhesions. Cells can actively generate these forces themselves using actin-myosin complexes which are part of their cytoskeleton. This is where substrate stiffness comes into play. On a hard substrate, cells generate large forces which leads to the formation of mature focal adhesions and a highly organized cytoskeleton with abundant stress fibers [45, 58]. In contrast, a soft substrate cannot provide enough resistance to counterbalance large, cell-generated forces. Therefore, on soft substrates cells do not develop abundant stress fibers and generate smaller forces. In other words, a cell responds to differences in substrate stiffness and adjusts its 'musculoskeletal system' (i.e. the cytoskeleton) appropriately.

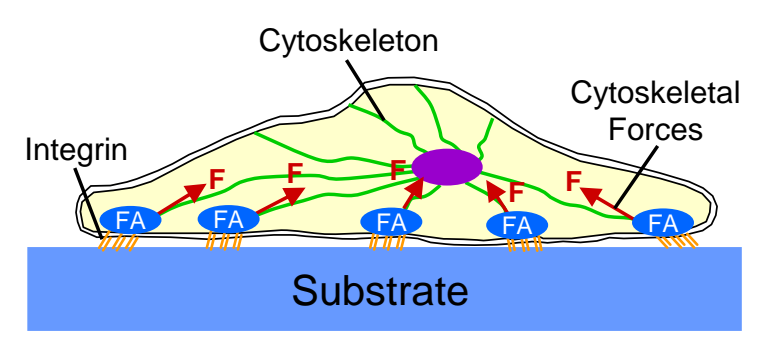

Fig. (2). Schematic representation of a cell which has attached to a substrate. Cells attach to a substrate with transmembrane molecules called integrins. When cells bind to a substrate, integrins begin to cluster which leads to the formation of focal adhesions (FA). The maturation of focal adhesions requires the application of mechanical forces $(\mathrm{F})$ to these adhesions which can be generated by the cytoskeleton.

Changes in cytoskeletal organization are important, because the cytoskeleton is involved in many signaling pathways that transfer mechanical feedback into chemical responses. Furthermore, the cytoskeleton also determines the 
shape of a cell, which in turn is intimately connected to cell behavior (reviewed in $[56,59]$ ). This was clearly demonstrated by cell biophysicist Christopher Chen and co-workers who showed that cell morphology can regulate differentiation of stem cells [60]. This group cultured stem cells on adhesive islands with different sizes to force stem cells to adopt a particular cell shape. On small islands, cell spreading was impaired due to space limitations, whereas cells normally spread on larger islands. In culture medium containing both adipogenic and osteogenic differentiation factors, it was found that cells became adipocytes on the small islands but committed to the osteogenic lineage on the large islands [60]. In other words, when these cells received culture medium supporting both osteogenic and adipogenic differentiation, the cell shape determined their fate. Even more intriguing, when cells were cultured on large islands in adipogenic medium, the cells still became osteogenic; vice versa, cells on small islands in osteogenic medium still became adipogenic. Thus, cell shape could drive stem cell differentiation and overrule the instructive messages provided by soluble differentiation factors. The cytoskeleton, in the form of actin-myosin generated tension proved to be essential in the stem cell commitment process.

\section{Substrate Stiffness and Cell Behavior}

Since substrate stiffness influences the cytoskeletal organization, it also affects cell morphology. Various studies indicated that stiffer substrates generally promote cell spreading, whereas soft substrates induce a more rounded cell shape (Fig. 3 and refs. [58,61,62]). From the above, it is not surprising that these changes in cell morphology are accompanied by changes in cell behavior, including cell differentiation. Discher and co-workers showed that muscle precursor cells optimally differentiate into myotubes on substrates with a stiffness that mimics that of muscle tissue [63, 64]. In addition, this group demonstrated that substrate stiffness can control the differentiation of stem cells [47]. Naïve mesenchymal stem cells were shown to specify lineage and commit to phenotypes with extreme sensitivity to substrate stiffness. Soft gels that mimic brain tissue are neurogenic, stiffer matrices that mimic muscle tissue are myogenic, and rigid gels prove osteogenic. During the initial week of culturing, reprogramming of these lineages is possible with the addition of soluable induction factors, but after several weeks in culture, the cells commit to the lineage specified by matrix stiffness [47].

Apart from changes in cell differentiation, the substrate stiffness also affects cell migration. This is important for the ingrowth of cells from host tissues, for example for the vascularization of a scaffold. It was reported that normal rat kidney epithelial cells and fibroblasts migrate faster on softer substrates compared to stiff substrates [49], whereas vascular smooth muscle cells showed maximal migration on intermediate stiff substrates [65]. It was demonstrated that these effects are mediated by changes in focal adhesion formation and myosin-generated forces [49]. Furthermore, when fibroblasts were cultured on a substrate with a soft and a stiff side, they preferred migrating into the direction of the stiff side (a phenomenon called 'durotaxis') [66]. Considering tissue formation, it was shown that fibroblasts merge to form tissue-like structures on soft substrates whereas these cells migrated away from one another on stiff substrates [67]. Similar behavior was observed for epithelial cell lines and explants from neonatal rat hearts. The driving force behind this merging of cells on soft substrates is a combination of weak adhesions and myosin II contraction [67].

\section{Soft (2.1 kPa) Stiff (68 kPa)}

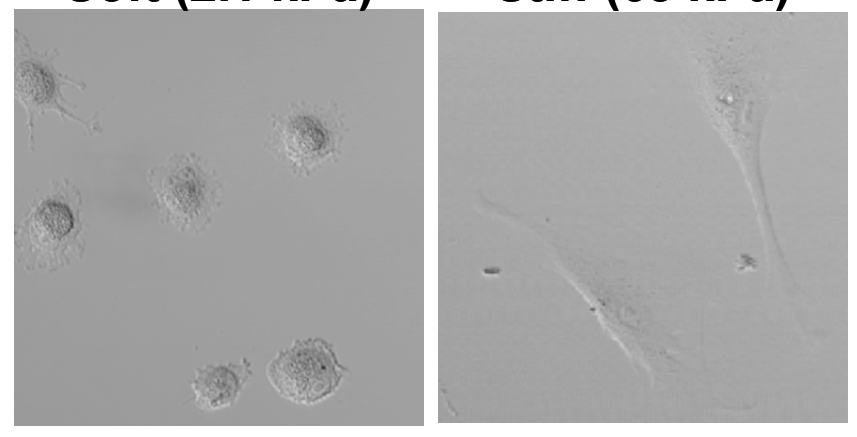

Fig. (3). Fibroblasts cultured in our lab on 'soft' and 'stiff' polyacrylamide gels coated with collagen I, four hours after plating. On a soft gel, cells adopted a round morphology whereas these cells spread on stiff gels.

Substrate stiffness also influences cell growth and viability. For example, osteoblasts showed increased proliferation, motility, and deposition of mineral on hard surfaces compared to soft substrates [68]. Importantly, the responses to substrate stiffness are different for normal and oncogenic cells. Non-transformed fibroblasts showed a decrease in the rate of DNA synthesis and an increase in the rate of apoptosis on soft substrates [69]. In contrast, transformed cells maintained their growth and apoptosis characteristics regardless of substrate rigidity. This indicates that feedback from substrate stiffness is required for proper regulation of cell growth and survival.

In the polyacrylamide gel system, cells are attached to a substrate as depicted in Fig. (2). This means that the cell only attaches to a substrate on one side, thus experiencing a two-dimensional (2D) situation. Recently, the effect of substrate stiffness on cell behavior was studied in threedimensional (3D) model systems [70-72], whereby cells are embedded in a gel consisting of ECM proteins. These 3D in vitro model systems provide a better representation of the $3 \mathrm{D}$ extracellular environment that cell encounter in vivo $[59,73]$. A drawback, however, is that it is difficult to independently control substrate stiffness and ECM biochemistry in these 3D systems. It appeared that matrix stiffness plays an important role in modifying cell behavior also in a 3D environment. For example, smooth muscle cell morphology was much rounder in stiff compared to soft 3D ECM analogs [71]. Interestingly, there can be important differences in cellular responses between $2 \mathrm{D}$ and $3 \mathrm{D}$ culture models. For example, the migration of human prostate cancer cells in $2 \mathrm{D}$ and $3 \mathrm{D}$ were shown to exhibit diametrically opposite behaviors [74].

In summary, current data demonstrate that substrate stiffness affects essential cell behavior including differentiation, migration, and growth. The 'musculoskeletal system' of the cell, i.e. the cytoskeleton, plays a crucial role in translating feedback from the substrate stiffness into cell behavior. 


\section{Substrate Stiffness and Biochemical Factors}

Only few studies investigated the combined effects of biochemical and biophysical factors on cell behavior. As already mentioned, cell shape and substrate stiffness can supersede biochemical signaling under certain conditions $[47,60]$. In addition, soluble induction factors appear to be less selective than matrix stiffness in driving stem cell differentiation, and cannot reprogram stem cells that were precommitted for weeks on a matrix with a certain stiffness [47]. On the other hand, a 'correct' substrate stiffness and soluble induction factors can combine to induce a more complete cell differentiation [47]. Considering substrate stiffness and ligand density (i.e. the availability of attachment sites), it was found that smooth muscle cells spread maximally on intermediate ligand densities on stiff substrates [62]. However, on soft substrates these cells were relatively insensitive to ligand density and showed a more rounded morphology [62]. Stimuli induced by specific ECM proteins also appear to be dependent on the stiffness of a substrate. It was found that collagen V, an ECM protein that is highly expressed during tissue development and repair, modifies cell morphology and migration on substrates with a tissue-like stiffness, but not on hard substrates (R.G.M. Breuls, submitted).

\section{OPPORTUNITIES FOR SKELETAL TISSUE ENGI- NEERING}

The ECM integrates many functions including the provision of structural support, attachment sites for cell surface receptors, and a reservoir for signaling molecules [75]. For a successful tissue engineering approach the complex tasks of the ECM need to be taken over by a scaffold material, which outlines the challenges for a scaffold designer. While it is virtually impossible to mimic the full complexity of the natural ECM, one may attempt to incorporate the most essential features in a scaffold. The stiffness of a scaffold appears to be one of these key variables.

\section{Mechanical Properties of a Scaffold}

When focusing on the mechanical properties, a scaffold should be strong enough to withstand the loads that act on a skeletal tissue at the defect site. Furthermore, the stiffness is important because it affects the strains acting on a cell while being attached to a scaffold [76]. For example, an extremely stiff titanium scaffold will clearly not transfer external loads to cells because it will not deform under physiologic loading conditions. However, the influence of mechanics on cell behavior is not limited to external loading. Even in the absence of external loads, the stiffness of a scaffold is important for the regulation of cell behavior.

Since substrate stiffness affects many different processes, such as cell growth, migration, and differentiation, it is difficult to provide a general guideline for a suitable scaffold stiffness that optimally stimulates tissue regeneration. Nevertheless, to optimally promote stem cell differentiation, current knowledge suggests that the scaffold stiffness should match the in vivo stiffness of the skeletal tissue under consideration. It is important to emphasize that a scaffold should probably exhibit the stiffness of a developing skeletal tissue, which might be lower than the stiffness of a mature tissue. To promote the invasion of the scaffold with cells from sur- rounding host tissue, a stiffer scaffold might be more favorable [66]. This may set conflicting requirements for the scaffold stiffness with respect to stem cell differentiation and invasion of host cells.

\section{Scaffold Surface Biochemistry}

Since substrate stiffness and biochemical stimuli interact to determine cell behavior, both parameters need to be controlled in scaffold design. Natural polymers such as collagen provide ligands for cell binding, however, the mechanical properties of these natural polymers are difficult to control. Synthetic polymers on the other hand generally offer the advantage of better control over the material properties but may require additional treatment to incorporate specific cell binding sites. By determination of the specific amino acid sequences of natural proteins that cells bind to, researchers were able to mimic cell binding sites in custom made peptide sequences that can be incorporated in synthetic scaffolds [77, 78]. Therefore, latest trends in scaffold design have been focusing on incorporating spatially well-defined cell binding sites in synthetic materials [79-82]. Such synthetic mimics of natural ECM materials have already been successfully applied for the regeneration of bone defects in rats [83, 84].

\section{Utilization of Scaffold Stiffness in Tissue Engineering Applications}

Most research on the use of stem cells in skeletal tissue engineering applications have relied on bone marrow derived stem cells. The use of stem cells extracted from bone marrow may require culturing of the stem cells in vitro in order to enrich and expand the stem cell population. Such procedures are costly and quality insurance in the clinical setting may be difficult to achieve. Cell culturing on conventional hard tissue culturing flasks might introduce another problem, however, since these hard materials can induce an undesired preconditioning of the stem cells as a consequence of an inappropriate stiffness [47]. Therefore, it might be useful to consider expansion of cells on substrates with a stiffness that compares to the stiffness of native tissue. However, cells may not proliferate on soft substrates that mimic native tissue. The problem is that cells either proliferate or synthesize matrix and differentiate at high rates. Stiff substrates seem to enhance proliferation, whereas soft substrates are more dedicated to differentiation.

The introduction of alternative sources for stem cells such as the adipose-derived stem cells may allow for a different approach that solves this problem [85, 86]. Adiposederived stem cells can be obtained in relative large quantities, which circumvents the need for cell culturing [87-89]. This has led to the formulation of a so-called one-step surgical procedure that avoids in vitro cell culturing [90]. In this procedure, stem cells are harvested form the patient, immediately seeded onto a scaffold, and implanted into the patient, all in a single surgical procedure. In this approach, an appropriate scaffold may circumvent undesired preconditioning of stem cells and, ideally, provide biochemical and mechanical stimuli that support the process of stem cell differentiation.

Generally speaking, most synthetic polymers that are currently used in orthopedic practice are stiff materials with elastic moduli in the range of $\sim 3$ to $2000 \mathrm{MPa}$ [91]. This 
suggests that these polymers could be suboptimal to stimulate stem cell differentiation, in particular for softer tissues. The latest trend, however, is that polymers such as PLA are used to create loosely packed fibrous meshes that have a much lower stiffness [92-98]. As a consequence, the cells 'feel' a relative low stiffness when they are embedded in these fibrous meshes. This opens up exciting new opportunities with these FDA-approved biodegradable materials. The tissue engineer may fabricate a scaffold with a stiffness that is suitable to promote the desired cell behavior. This might be the stimulation of cell proliferation, differentiation, or even the migration of host cells, depending on the specific requirements in situ. Obviously, a vast amount of research is needed to further investigate the effects of substrate stiffness in combination with other variables such as pore size in the context of these fibrous meshes.

\section{CLOSING REMARKS}

Recently, the proof of concept of stem cell based approaches in orthopaedics has been demonstrated in animal models. However, at present, only very few studies on humans exists [99-101], which had only limited success [17]. Possibly, a better understanding of the complex multifactorial process regulating stem cell behavior may lead to the often anticipated breakthrough in tissue engineering. This review focused on the importance of the stiffness of a scaffold in tissue engineering applications. Scaffold stiffness can guide stem cell differentiation and affects cell migration, the latter being important with respect to cell infiltration from host tissues. Although biochemical stimuli are clearly very important in the regulation of cell behavior, it has become clear that a scaffold with an inappropriate stiffness may frustrate the process of tissue regeneration. On the other hand, a scaffold with a well-chosen stiffness can stimulate the regeneration of new tissue and enhance the efficacy of biochemical stimuli. Thus, the scaffold stiffness may be an important variable to control stem cell behavior which provides new opportunities for tissue engineering.

\section{ACKNOWLEDGEMENT}

Roel Breuls was supported by the Dutch Program for Tissue Engineering, project BGT.6734.

\section{REFERENCES}

[1] Hollinger JO, Brekke J, Gruskin E, Lee D. Role of bone substitutes. Clin Orthop Relat Res 1996; (324): 55-65.

[2] Chen YC, Chen CH, Chen PL, Huang IY, Shen YS, Chen CM. Donor site morbidity after harvesting of proximal tibia bone. Head Neck 2006; 28(6): 496-500.

[3] Farhadi J, Valderrabano V, Kunz C, Kern R, Hinterman B, Pierer G. Free fibula donor-site morbidity: clinical and biomechanical analysis. Ann Plast Surg 2007; 58(4): 405-10.

[4] Kirmeier R, Payer M, Lorenzoni M, Wegscheider WA, Seibert FJ, Jakse N. Harvesting of cancellous bone from the proximal tibia under local anesthesia: donor site morbidity and patient experience. $\mathrm{J}$ Oral Maxillofac Surg 2007; 65(11): 2235-41.

[5] LaPrade RF, Botker JC. Donor-site morbidity after osteochondral autograft transfer procedures. Arthroscopy 2004; 20(7): e69-e73.

[6] Mischkowski RA, Domingos-Hadamitzky C, Siessegger M, Zinser MJ, Zoller JE. Donor-site morbidity of ear cartilage autografts. Plast Reconstr Surg 2008; 121(1): 79-87.

[7] Corbi C, Traineau R, Esperou H, et al. Prevalence and clinical features of hepatitis $\mathrm{G}$ virus infection in bone marrow allograft recipients. Bone Marrow Transplant 1997; 20(11): 965-8.
[8] Nemzek JA, Arnoczky SP, Swenson CL. Retroviral transmission in bone allotransplantation. The effects of tissue processing. Clin Orthop Relat Res 1996; (324): 275-82.

[9] Nemzek JA, Arnoczky SP, Swenson CL. Retroviral transmission by the transplantation of connective-tissue allografts. An experimental study. J Bone Joint Surg Am 1994; 76(7): 1036-41.

[10] Cook SD, Salkeld SL, Prewett AB. Simian immunodeficiency virus (human HIV-II) transmission in allograft bone procedures. Spine 1995; 20(12): 1338-42.

[11] Sanzen L, Carlsson A. Transmission of human T-cell lymphotrophic virus type 1 by a deep-frozen bone allograft. Acta Orthop Scand 1997; 68(1): 72-4.

[12] Rezwan K, Chen QZ, Blaker JJ, Boccaccini AR. Biodegradable and bioactive porous polymer/inorganic composite scaffolds for bone tissue engineering. Biomaterials 2006; 27(18): 3413-31.

[13] Hutmacher DW. Scaffolds in tissue engineering bone and cartilage. Biomaterials 2000; 21(24): 2529-43.

[14] Burg KJ, Porter S, Kellam JF. Biomaterial developments for bone tissue engineering. Biomaterials 2000; 21(23): 2347-59.

[15] Agrawal CM, Ray RB. Biodegradable polymeric scaffolds for musculoskeletal tissue engineering. J Biomed Mater Res 2001; 55(2): 141-50.

[16] Badylak SF. The extracellular matrix as a scaffold for tissue reconstruction. Semin. Cell Dev Biol 2002; 13(5): 377-83.

[17] Meijer GJ, de Bruijn JD, Koole R, van Blitterswijk CA. Cell-based bone tissue engineering. PLoS Med 2007; 4(2): e9.

[18] Mauney JR, Volloch V, Kaplan DL. Role of adult mesenchymal stem cells in bone tissue engineering applications: current status and future prospects. Tissue Eng 2005; 11(5-6): 787-802.

[19] Wozney JM, Rosen V. Bone morphogenetic protein and bone morphogenetic protein gene family in bone formation and repair. Clin Orthop Relat Res 1998; (346): 26-37.

[20] Wozney JM, Rosen V, Celeste AJ, et al. Novel regulators of bone formation: molecular clones and activities. Science 1988; 242(4885): 1528-34.

[21] Reddi AH. Cartilage morphogenetic proteins: role in joint development, homoeostasis, and regeneration. Ann Rheum Dis 2003; 62(Suppl 2): 273-78.

[22] Reddi AH. Cartilage morphogenesis: role of bone and cartilage morphogenetic proteins, homeobox genes and extracellular matrix. Matrix Biol 1995; 14(8): 599-606.

[23] Reddi AH. Regulation of cartilage and bone differentiation by bone morphogenetic proteins. Curr Opin Cell Biol 1992; 4(5): 850-5.

[24] Lieberman JR, Daluiski A, Einhorn TA. The role of growth factors in the repair of bone. Biology and clinical applications. J Bone Joint Surg Am 2002; 84-A(6): 1032-44.

[25] Watt FM, Hogan BL. Out of Eden: stem cells and their niches. Science 2000; 287(5457): 1427-30.

[26] Lin CQ, Bissell MJ. Multi-faceted regulation of cell differentiation by extracellular matrix. FASEB J 1993; 7(9): 737-43.

[27] Datta N, Holtorf HL, Sikavitsas VI, Jansen JA, Mikos AG. Effect of bone extracellular matrix synthesized in vitro on the osteoblastic differentiation of marrow stromal cells. Biomaterials 2005; 26(9): 971-7.

[28] Czyz J, Wobus A. Embryonic stem cell differentiation: the role of extracellular factors. Differentiation 2001; 68(4-5): 167-74.

[29] Streuli C. Extracellular matrix remodelling and cellular differentiation. Curr Opin Cell Biol 1999; 11(5): 634-40.

[30] Estes BT, Gimble JM, Guilak F. Mechanical signals as regulators of stem cell fate. Curr Top Dev Biol 2004; 60: 91-126.

[31] Malone AM, Narain R, Jacobs CR. Biomechanical regulation of mesenchymal stem cell and progenitor cells and the implications for regenerative medicine. Curr Opin Orthop 2005; 163: 63-7.

[32] Settleman J. Tension proceeds commitment-even for a stem cell. Mol Cell 2004; 14(2): 148-50.

[33] Ingber DE. Mechanobiology and diseases of mechanotransduction. Ann Med 2003; 35(8): 564-77.

[34] Saha S, Ji L, De PJ, Palecek S. TGF- $\beta /$ Activin/Nodal Inhibition of human embryonic stem cell differentiation by mechanical strain. Biophys J 2008; 94(10): 4123-33.

[35] Saha S, Ji L, de Pablo JJ, Palecek SP. Inhibition of human embryonic stem cell differentiation by mechanical strain. J Cell Physiol 2006; 206(1): 126-37.

[36] Kunzler TP, Drobek T, Schuler M, Spencer ND. Systematic study of osteoblast and fibroblast response to roughness by means of surface-morphology gradients. Biomaterials 2007; 28(13): 2175-82. 
[37] Washburn NR, Yamada KM, Simon CG Jr, Kennedy SB, Amis EJ. High-throughput investigation of osteoblast response to polymer crystallinity: influence of nanometer-scale roughness on proliferation. Biomaterials 2004; 25(7-8): 1215-24.

[38] Boyan BD, Lohmann CH, Dean DD, Sylvia VL, Cochran DL, Schwartz Z. Mechanisms involved in osteoblast response to implant surface morphology. Ann Rev Mater Res 2001; 31:357-71.

[39] Kunzler TP, Huwiler C, Drobek T, Voros J, Spencer ND. Systematic study of osteoblast response to nanotopography by means of nanoparticle-density gradients. Biomaterials 2007; 28(33): 5000-6.

[40] Boyan BD, Bonewald LF, Paschalis EP, et al. Osteoblast-mediated mineral deposition in culture is dependent on surface microtopography. Calcif Tissue Int 2002; 71(6): 519-29.

[41] Karageorgiou V, Kaplan D. Porosity of 3D biomaterial scaffolds and osteogenesis. Biomaterials 2005; 26(27): 5474-91.

[42] Wake MC, Patrick CW, Jr., Mikos AG. Pore morphology effects on the fibrovascular tissue growth in porous polymer substrates. Cell Transplant 1994; 3(4): 339-43.

[43] Holtorf HL, Datta N, Jansen JA, Mikos AG. Scaffold mesh size affects the osteoblastic differentiation of seeded marrow stromal cells cultured in a flow perfusion bioreactor. J Biomed Mater Res A 2005; 74(2): 171-80.

[44] Zeltinger J, Sherwood JK, Graham DA, Mueller R, Griffith LG. Effect of pore size and void fraction on cellular adhesion, proliferation, and matrix deposition. Tissue Eng 2001; 7(5): 557-72.

[45] Discher DE, Janmey P, Wang YL. Tissue cells feel and respond to the stiffness of their substrate. Science 2005; 310(5751): 1139-43.

[46] Rehfeldt F, Engler AJ, Eckhardt A, Ahmed F, Discher DE. Cell responses to the mechanochemical microenvironment--implications for regenerative medicine and drug delivery. Adv Drug Deliv Rev 2007; 59(13): 1329-39.

[47] Engler AJ, Sen S, Sweeney HL, Discher DE. Matrix elasticity directs stem cell lineage specification. Cell 2006; 126(4): 677-89.

[48] Beningo KA, Wang YL. Flexible substrata for the detection of cellular traction forces. Trends Cell Biol 2002; 12(2): 79-84.

[49] Pelham RJ, Jr., Wang Y. Cell locomotion and focal adhesions are regulated by substrate flexibility. Proc Natl Acad Sci USA 1997; 94(25): 13661-5.

[50] Wang YL, Pelham RJ, Jr. Preparation of a flexible, porous polyacrylamide substrate for mechanical studies of cultured cells. Methods Enzymol 1998; 29: 8489-96.

[51] Wong JY, Leach JB, Brown XQ. Balance of chemistry, topography, and mechanics at the cell-biomaterial interface: Issues and challenges for assesing the role of substrate mechanics on cell response. Surface Science 2004; 570: 119-33.

[52] Wang N, Butler JP, Ingber DE. Mechanotransduction across the cell surface and through the cytoskeleton. Science 1993; 260 (5111): 1124-7.

[53] Chen CS, Ingber DE. Tensegrity and mechanoregulation: from skeleton to cytoskeleton. Osteoarthritis Cartilage 1999; 7(1): 81-94.

[54] Chen CS, Tan J, Tien J. Mechanotransduction at cell-matrix and cell-cell contacts. Annu Rev Biomed Eng 2004; 6275-302.

[55] Forgacs G, Yook SH, Janmey PA, Jeong H, Burd CG. Role of the cytoskeleton in signaling networks. J Cell Sci 2004; 117(Pt 13): 2769-75.

[56] Janmey PA. The cytoskeleton and cell signaling: component localization and mechanical coupling. Physiol Rev 1998; 78(3): 763-81.

[57] Alenghat FJ, Ingber DE. Mechanotransduction: all signals point to cytoskeleton, matrix, and integrins. Sci STKE 2002; 2002(119): PE6.

[58] Yeung T, Georges PC, Flanagan LA, et al. Effects of substrate stiffness on cell morphology, cytoskeletal structure, and adhesion. Cell Motil Cytoskeleton 2005; 60(1): 24-34

[59] Cukierman E, Pankov R, Yamada KM. Cell interactions with threedimensional matrices. Curr Opin Cell Biol 2002; 14(5): 633-9.

[60] McBeath R, Pirone DM, Nelson CM, Bhadriraju K, Chen CS. Cell shape, cytoskeletal tension, and RhoA regulate stem cell lineage commitment. Dev Cell 2004; 6(4): 483-95.

[61] Gaudet C, Marganski WA, Kim S, et al. Influence of type I collagen surface density on fibroblast spreading, motility, and contractility. Biophys J 2003; 85(5): 3329-35.

[62] Engler A, Bacakova L, Newman C, Hategan A, Griffin M, Discher D. Substrate compliance versus ligand density in cell on gel responses. Biophys J 2004; 86(1 Pt 1): 617-28.

[63] Engler AJ, Griffin MA, Sen S, Bonnemann CG, Sweeney HL, Discher DE. Myotubes differentiate optimally on substrates with tissue-like stiffness: pathological implications for soft or stiff microenvironments. J Cell Biol 2004; 166(6): 877-87.

[64] Griffin MA, Sen S, Sweeney HL, Discher DE. Adhesioncontractile balance in myocyte differentiation. J Cell Sci 2004; 117(Pt 24): 5855-63.

[65] Peyton SR, Putnam AJ. Extracellular matrix rigidity governs smooth muscle cell motility in a biphasic fashion. J Cell Physiol 2005; 204(1): 198-209.

[66] Lo CM, Wang HB, Dembo M, Wang YL. Cell movement is guided by the rigidity of the substrate. Biophys J 2000; 79(1): 144-52.

[67] Guo WH, Frey MT, Burnham NA, Wang YL. Substrate rigidity regulates the formation and maintenance of tissues. Biophys J 2006; 90(6): 2213-20.

[68] Khatiwala CB, Peyton SR, Putnam AJ. Intrinsic mechanical properties of the extracellular matrix affect the behavior of preosteoblastic MC3T3-E1 cells. Am J Physiol Cell Physiol 2006; 290(6): 1640-50

[69] Wang HB, Dembo M, Wang YL. Substrate flexibility regulates growth and apoptosis of normal but not transformed cells. Am J Physiol Cell Physiol 2000; 279(5): 1345-50.

[70] Shapira-Schweitzer K, Seliktar D. Matrix stiffness affects spontaneous contraction of cardiomyocytes cultured within a PEGylated fibrinogen biomaterial. Acta Biomater 2007; 3(1): 33-41.

[71] Dikovsky D, Bianco-Peled H, Seliktar D. Defining the role of matrix compliance and proteolysis in three-dimensional cell spreading and remodeling. Biophys J 2008; 94(7): 2914-25.

[72] Ghosh K, Pan Z, Guan E, et al. Cell adaptation to a physiologically relevant ECM mimic with different viscoelastic properties. Biomaterials 2007; 28(4): 671-9.

[73] Cukierman E, Pankov R, Stevens DR, Yamada KM. Taking cellmatrix adhesions to the third dimension. Science 2001; 294(5547): 1708-12.

[74] Zaman MH, Trapani LM, Sieminski AL, et al. Migration of tumor cells in 3D matrices is governed by matrix stiffness along with cellmatrix adhesion and proteolysis. Proc Natl Acad Sci USA 2006; 103(29): 10889-94.

[75] Kleinman HK, Philp D, Hoffman MP. Role of the extracellular matrix in morphogenesis. Curr Opin Biotechnol 2003; 14(5): 52632.

[76] Baas E, Kuiper J, Yang Y, Wood MA, El-Haj AJ. In vitro bone growth responds to tissue-level mechanical strain in threedimensional polymer scaffolds. 54th Annual Meeting Orthopaedic Research Society 2008; 72.

[77] van Hest JC, Tirrell DA. Protein-based materials, toward a new level of structural control. Chem Commun (Camb) 2001; (19): 1897-904.

[78] Pierschbacher MD, Ruoslahti E. Cell attachment activity of fibronectin can be duplicated by small synthetic fragments of the molecule. Nature 1984; 309(5963): 30-3.

[79] Langer R, Tirrell DA. Designing materials for biology and medicine. Nature 2004; 428(6982): 487-92.

[80] Lutolf MP, Hubbell JA. Synthetic biomaterials as instructive extracellular microenvironments for morphogenesis in tissue engineering. Nat Biotechnol 2005; 23(1): 47-55.

[81] Shin H, Jo S, Mikos AG. Biomimetic materials for tissue engineering. Biomaterials 2003; 24(24): 4353-64.

[82] Hersel U, Dahmen C, Kessler H. RGD modified polymers: biomaterials for stimulated cell adhesion and beyond. Biomaterials 2003 24(24): 4385-415.

[83] Lutolf MP, Weber FE, Schmoekel HG, et al. Repair of bone defects using synthetic mimetics of collagenous extracellular matrices. Nat Biotechnol 2003; 21(5): 513-8.

[84] Pratt AB, Weber FE, Schmoekel HG, Muller R, Hubbell JA. Synthetic extracellular matrices for in situ tissue engineering. Biotechnol Bioeng 2004; 86(1): 27-36.

[85] Zuk PA. Tissue engineering craniofacial defects with adult stem cells? Are we ready yet? Pediatr Res 2008; 63(5): 478-86.

[86] Zuk PA, Zhu M, Ashjian P, et al. Human adipose tissue is a source of multipotent stem cells. Mol Biol Cell 2002; 13(12): 4279-95.

[87] Mitchell JB, McIntosh K, Zvonic S, et al. Immunophenotype of human adipose-derived cells: temporal changes in stromalassociated and stem cell-associated markers. Stem Cells 2006; 24(2): 376-85

[88] Guilak F, Lott KE, Awad HA, et al. Clonal analysis of the differentiation potential of human adipose-derived adult stem cells. J Cell Physiol 2006; 206(1): 229-37. 
[89] Varma MJ, Breuls RG, Schouten TE, et al. Phenotypical and functional characterization of freshly isolated adipose tissue-derived stem cells. Stem Cells Dev 2007; 16(1): 91-104.

[90] Helder MN, Knippenberg M, Klein-Nulend J, Wuisman PI. Stem cells from adipose tissue allow challenging new concepts for regenerative medicine. Tissue Eng 2007; 13(8): 1799-808.

[91] Engelberg I, Kohn J. Physico-mechanical properties of degradable polymers used in medical applications: a comparative study. Biomaterials 1991; 12(3): 292-304

[92] Janjanin S, Li WJ, Morgan MT, Shanti RM, Tuan RS. Moldshaped, nanofiber scaffold-based cartilage engineering using human mesenchymal stem cells and Bioreactor. J Surg Res 2008; [Epub ahead of print].

[93] Li WJ, Laurencin CT, Caterson EJ, Tuan RS, Ko FK. Electrospun nanofibrous structure: a novel scaffold for tissue engineering. $\mathrm{J}$ Biomed Mater Res 2002; 60(4): 613-21.

[94] Li WJ, Mauck RL, Cooper JA, Yuan X, Tuan RS. Engineering controllable anisotropy in electrospun biodegradable nanofibrous scaffolds for musculoskeletal tissue engineering. J Biomech 2007; 40(8): 1686-93.

[95] Li WJ, Jiang YJ, Tuan RS. Chondrocyte phenotype in engineered fibrous matrix is regulated by fiber size. Tissue Eng 2006; 12(7): 1775-85.
[96] Li WJ, Tuli R, Huang X, Laquerriere P, Tuan RS. Multilineage differentiation of human mesenchymal stem cells in a threedimensional nanofibrous scaffold. Biomaterials 2005; 26(25): 5158-66.

[97] Li WJ, Tuli R, Okafor C, et al. A three-dimensional nanofibrous scaffold for cartilage tissue engineering using human mesenchymal stem cells. Biomaterials 2005; 26(6): 599-609.

[98] Li WJ, Danielson KG, Alexander PG, Tuan RS. Biological response of chondrocytes cultured in three-dimensional nanofibrous poly(epsilon-caprolactone) scaffolds. J Biomed Mater Res A 2003; 67(4): 1105-14.

[99] Cancedda R, Bianchi G, Derubeis A, Quarto R. Cell therapy for bone disease: a review of current status. Stem Cells 2003; 21(5): 610-9.

[100] Quarto R, Mastrogiacomo M, Cancedda R, et al. Repair of large bone defects with the use of autologous bone marrow stromal cells. N Engl J Med 2001; 344(5): 385-6.

[101] Schmelzeisen R, Schimming R, Sittinger M. Soft tissue and hard tissue. engineering in oral and maxillofacial surgery. Ann R Australas Coll Dent Surg 2002; 1650-3.

(C) Breuls et al.; Licensee Bentham Open.

This is an open access article distributed under the terms of the Creative Commons Attribution License (http://creativecommons.org/licenses/by/2.5/), which permits unrestrictive use, distribution, and reproduction in any medium, provided the original work is properly cited. 